\title{
Mendoza, ciudad compacta versus metrópolis sin oasis.
}

\section{Gladys Edith Molina', Mariela Edith Arboit ${ }^{2}$, Dora Silvia Maglione ${ }^{3}$, Ana Sedevich ${ }^{4}$}

${ }^{124}$ Instituto de Ciencias Humanas, Sociales y Ambientales (INCIHUSA).Consejo Nacional de Investigaciones Científicas y Técnicas (CONICET), Argentina. ${ }^{3}$ Instituto de Trabajo, Economía y

Territorio Universidad Nacional de la Patagonia Austral, Argentina

E-mail: 19molina@mendoza-conicet.gob.ar, ${ }^{2}$ marboit@mendoza-conicet.gob.ar,

${ }^{3}$ dmaglione@uarg.unpa.edu.ar, ${ }^{4}$ anasedevich@mendoza-conicet.gob.ar

\begin{abstract}
Resumen. La urbanización es uno de los principales factores antropogénicos que ha causado la reducción de la superficie verde y la sustitución de los hábitats preexistentes en las ciudades. Más de la mitad de la población humana mundial se concentra en zonas urbanas y la región de América Latina es una de las más urbanizadas, con el 80\% de población en ciudades. En lugares de ecosistemas frágiles, el crecimiento extensivo resulta crítico para la misma sostenibilidad humana, como el caso de Mendoza. Esta ciudad con más de un millón de habitantes, crece a expensas de un oasis reducido mientras la gestión gubernamental fragmentada en 6 municipios, admite que es necesario renovar las formas de intervención territorial. Las investigaciones recientes se abocan al análisis en las zonas urbanas residenciales, estudiando los diseños urbanos y el impacto generado por los modelos de crecimiento urbano vigentes, no siempre coincidentes con modelos de desarrollo. En este caso se propone una mirada sistémica que permite poner a la luz los procesos espaciales que resultaron de las cambiantes políticas aplicadas al Área Metropolitana de Mendoza (AMM) Argentina, en los últimos 50 años. Tres delimitaciones de la forma urbana, permiten analizar la expansión urbano-edilicia y el crecimiento demográfico en el período señalado, con su impacto sobre la componente ambiental del índice de vegetación y sobre los consumos energéticos. Condiciones ambientales restrictivas se conjugan con una normativa ambiciosa frente a unas prácticas sociales individualistas, dando resultados contradictorios. Es por eso que, para proponer una re ingeniería de intervención, hay que volver a dimensionar la incidencia de las herramientas posibles.
\end{abstract}

\section{Redensificación, compactación urbana, lineamientos de} crecimiento, sostenibilidad energético-ambiental.

\section{Introducción}

De acuerdo con diagnósticos diversos y estudios realizados desde diferentes aportes disciplinares, el AMM presenta una estructura urbana caracterizada como ciudad dispersa, con baja densidad general y desigual acceso a los servicios básicos para la población. De aquí se desprende que el crecimiento deseable debería orientarse a aprovechar áreas vacantes dentro de los espacios ya urbanizados y decidir qué umbrales de densidad conviene hacia la periferia del área metropolitana.

En este trabajo se toman tres delimitaciones de la forma urbana, permiten analizar la expansión urbano-edilicia y el crecimiento demográfico en los últimos 50 años, con su impacto sobre la componente ambiental del índice de vegetación y sobre los consumos energéticos. La respuesta ante la disyuntiva de orientar el crecimiento futuro de la metrópolis mediante la re-densificación o mediante la 
expansión de baja densidad surge así de la consideración del área metropolitana en el marco geográfico de referencia, su entorno rural.

Se incorpora la dimensión temporal para los últimos 50 años porque es entonces cuando la disyuntiva se presenta. La ciudad de Mendoza es heredera de largos siglos de simbiosis entre el hombre y su medio, durante la época colonial creció lentamente pautada por las normativas impuestas y dependiendo de la provisión de agua por acequias. Durante los siglos XIX y XX, se aceleran los impactos de factores de progreso como el ferrocarril, la inmigración y la expansión agrícola basada en el riego. Pero actualmente, desde hace ya unas cuantas décadas, son los factores culturales y económicos los que ganan el protagonismo a costa de degradar y consumir el oasis y el sutil equilibrio ambiental.

\section{Metodología}

La propuesta metodológica surge a partir de la confrontación de tres líneas de investigación que tratan la problemática del crecimiento urbano de la metrópolis mendocina a partir de tres fuentes de información diferente, cartografía, censos e imágenes satelitales. Las tres delimitaciones analizadas tienen una similitud general pero representan tres aspectos diferentes del uso urbano del suelo: la subdivisión de los terrenos, la densidad de población y la infraestructura energética (Figura 1).

A partir de catastro digital o de imágenes de planos históricos, la cartografía permite deducir la historia de la ciudad porque expresa las configuraciones producidas en cada época y la velocidad con que las parcelas se subdividen, indicando cambios de lo rural a lo urbano. Tal subdivisión depende no sólo de la decisión individual sino de los marcos legales que avalan o impiden los loteos. Al comparar varios tiempos en el estado de subdivisión de los terrenos, se pueden identificar elementos del espacio construido (rutas, ríos, canales, entre otros) que van estructurando la expansión de la ciudad.

La distribución de densidades de población, da la posibilidad de diferenciar lo urbano de lo rural y también permite evaluar el grado de intensidad con que se están aprovechando las áreas de la ciudad. Por supuesto, como los valores absolutos se destacan o se disimulan dependiendo del tamaño de la superficie de referencia, hay cierta relatividad en el manejo de la información. Sin embargo, lo valioso de esta fuente es la periodicidad de los relevamientos, que permite medir, comparar e identificar las tendencias en la decisión de las personas y por eso va perfilando los ciclos de aceleración, retracción o cambios de dirección en la dinámica poblacional.

Las imágenes satelitales, con la precisión de la teledetección y la variedad de temáticas que se pueden asociar, da la posibilidad de observar los elementos visibles tanto naturales como construidos. Se aplican filtros para delimitar la silueta urbana a partir de la radiación lumínica. Los indicadores cuantitativos para medir los aportes energéticos al ambiente en

\begin{tabular}{|l|l|}
\hline $\begin{array}{l}\text { Contorno urbano, fuente } \\
\text { catastral. 2017. Áreas } \\
\text { afectadas por parcelas } \\
\text { urbanas. }\end{array}$ & $\begin{array}{l}\text { Contorno urbano, fuente } \\
\text { censal. 2010. Radios censales } \\
\text { con más de 4 habitantes por } \\
\text { hectárea. }\end{array}$ \\
\hline Figura 1: Tres delimitaciones de la silueta urbana del Área Metropolitana de Mendoza. \\
\hline
\end{tabular}




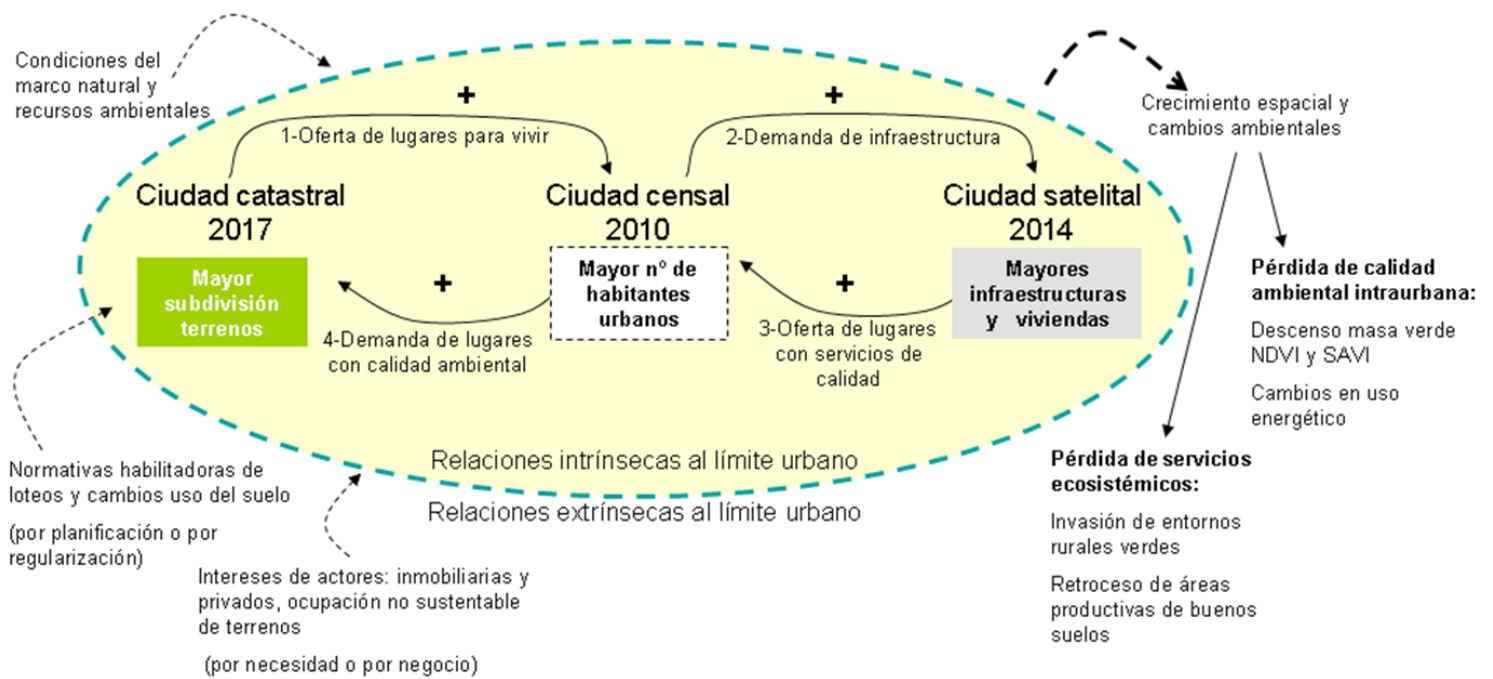

Fig. 2. esquema metodológico

los departamentos, son los consumos de gas y electricidad.

Se incorpora la dimensión temporal para visualizar el proceso espacial (cambios en la superficie cubierta) en paralelo con factores estructurantes como el marco legal de loteos; la dinámica poblacional (cambios en la densidad de habitantes) en relación con las políticas de vivienda; la evolución de los consumos energéticos en correlación con la población, superficie y cambios en la cobertura de masa verde. (Figura 2).

Las relaciones sistémicas entre estas tres líneas de investigación se sintetizan en un esquema acotado a la escala urbana, donde se indican los encadenamientos más relevantes. La subdivisión del suelo, genera una oferta de lotes que la población aprovecha para cubrir sus requerimientos de vivienda. La radicación de esos nuevos pobladores produce demandas de infraestructura (como luz, agua potable, gas y otros servicios). Una vez realizados estos desarrollos, se convierten en una buena oferta de condiciones que favorecen y atraen más población. Sin embargo, con el crecimiento de espacios construidos y aumento de actividades urbanas se generan otras demandas que viran el interés hacia los aspectos ambientales como calidad del aire, entornos arbolados, espacios públicos para diferentes finalidades. En definitiva, después de varios eslabones de decisiones que sobrecargan los terrenos, si no actúan los controles de gobierno, el resultado es una rápida ampliación de la superficie urbanizada.

El esquema representa la lógica empleada para la interpretación de resultados, diferenciando las tres delimitaciones de la silueta urbana, los indicadores seleccionados como in put y los output.

\section{Resultados analíticos: A partir de la fuente catastral}

De acuerdo con la información cartográfica, la ciudad en 1970 presentaba una silueta más o menos compacta, con las extensiones propias de la influencia de las grandes vías de acceso como ruta nacional 7 , ruta nacional 40 y la conexión hacia el sureste. Todavía se identificaba la discontinuidad espacial de algunas cabeceras de departamentos vecinos, como Maipú y Luján. Durante las siguientes dos décadas se engrosaron esas extensiones tipo pinzas, y ya en este siglo el proceso espacial produce el relleno de intersticios y la aparición de nuevas pinzas. Capital y Godoy Cruz, en el corazón de la metrópolis frenan su expansión, tal como indica la curva de la figura 3.

Se ajustaron los valores del área urbanizada para cada departamento del AMM mediante a una recta de regresión lineal, en la tabla 1 se presenta el modelo obtenido junto con el coeficiente de determinación. Los resultados indican una tendencia general ascendente del área urbanizada en la totalidad de los departamentos. La mayor pendiente de crecimiento se registró en Guaymallén, seguido 


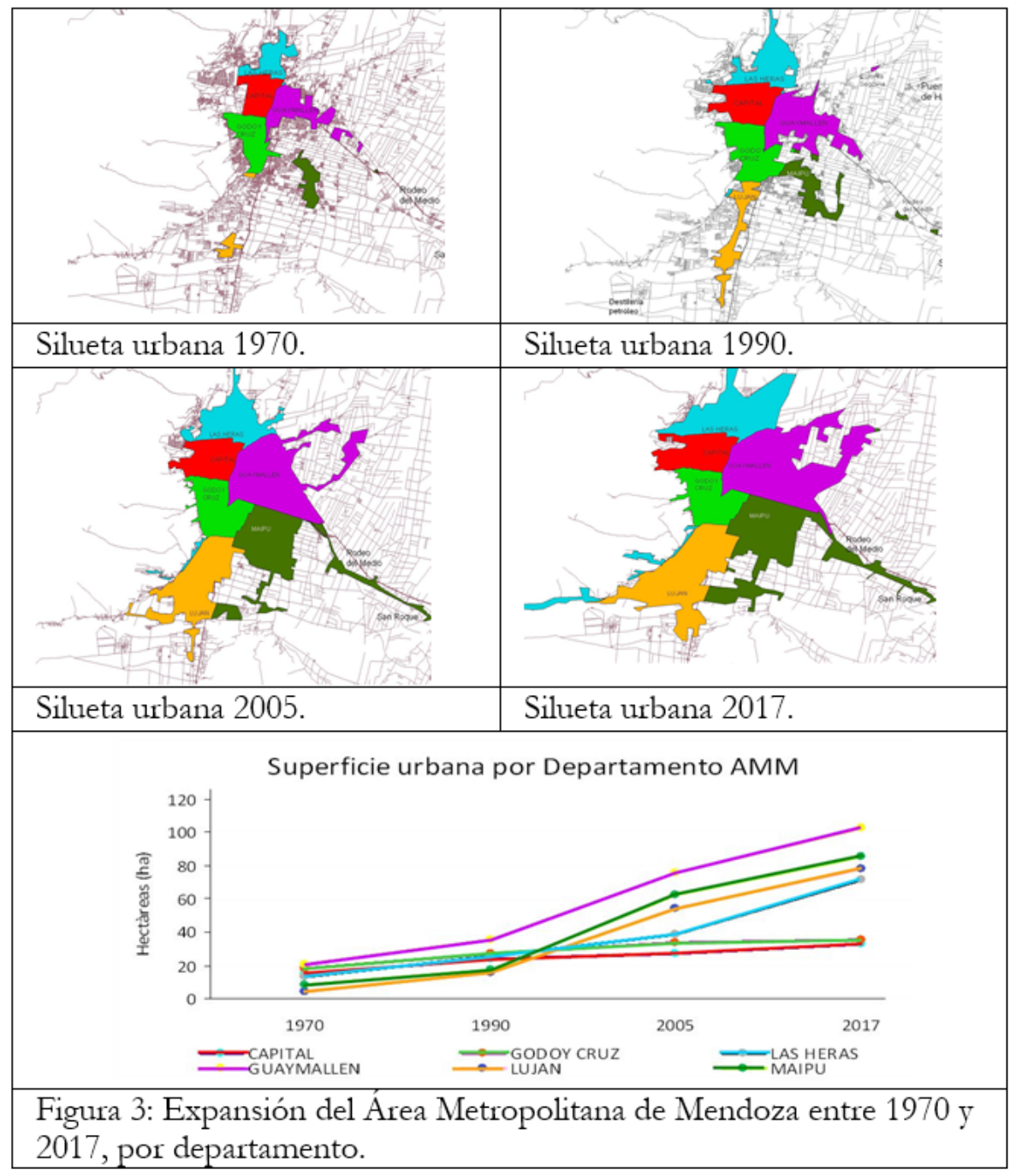

por Maipú y Luján de Cuyo.

Se ajustaron los valores del área urbanizada para cada departamento del AMM mediante a una recta de regresión lineal, en la tabla 1 se presenta el modelo obtenido junto con el coeficiente de determinación. Los resultados indican una tendencia general ascendente del área urbanizada en la totalidad de los departamentos. La mayor pendiente de crecimiento se registró en Guaymallén, seguido por Maipú y Luján de Cuyo.

\section{A partir de la fuente censal}

Los umbrales de densidad de población dibujan una silueta sugerente: una ciudad compacta con densidades superiores a $30 \mathrm{hab} /$ ha que mantiene la contigüidad de Capital con Las Heras, Guaymallén, Godoy Cruz y Maipú, pero no así con Luján. El umbral de 60 hab/ ha marca unos mosaicos que van dejando un centro capitalino con tendencia al descenso de densidad poblacional. Lo cual sugiere que, si la densidad edilicia es más compacta en el centro, es porque están cumpliendo funciones comerciales y administrativas y no tanto residenciales.

\begin{tabular}{|c|c|c|}
\hline & $\mathrm{R}^{2}$ & $\begin{array}{l}\text { Recta ajustada y } \\
\text { coeficiente de determinación }\end{array}$ \\
\hline Capital & 0.98 & SupUrb $=-708,95+0,37$ año $(* *)$ \\
\hline Godoy Cruz & 0.98 & SupUrb $=-711,43+0,37$ año $(*)$ \\
\hline Guaymallén & 0.93 & $\operatorname{SupU}_{\mathrm{rb}}=-3515,38+1,79$ año $(*)$ \\
\hline Las Heras & 0.88 & SupUrb $=-2263,42+1,15$ año $()$. \\
\hline Luján de Cuyo & 0.92 & SupUtrb $=-3209,17+1,63$ año $(*)$ \\
\hline Maipú & 0.90 & SupUrb $=-3381,42+1,72$ año $()$. \\
\hline
\end{tabular}

Tab. 1. Recta ajustada y coeficiente de determinación para expansión urbana. 


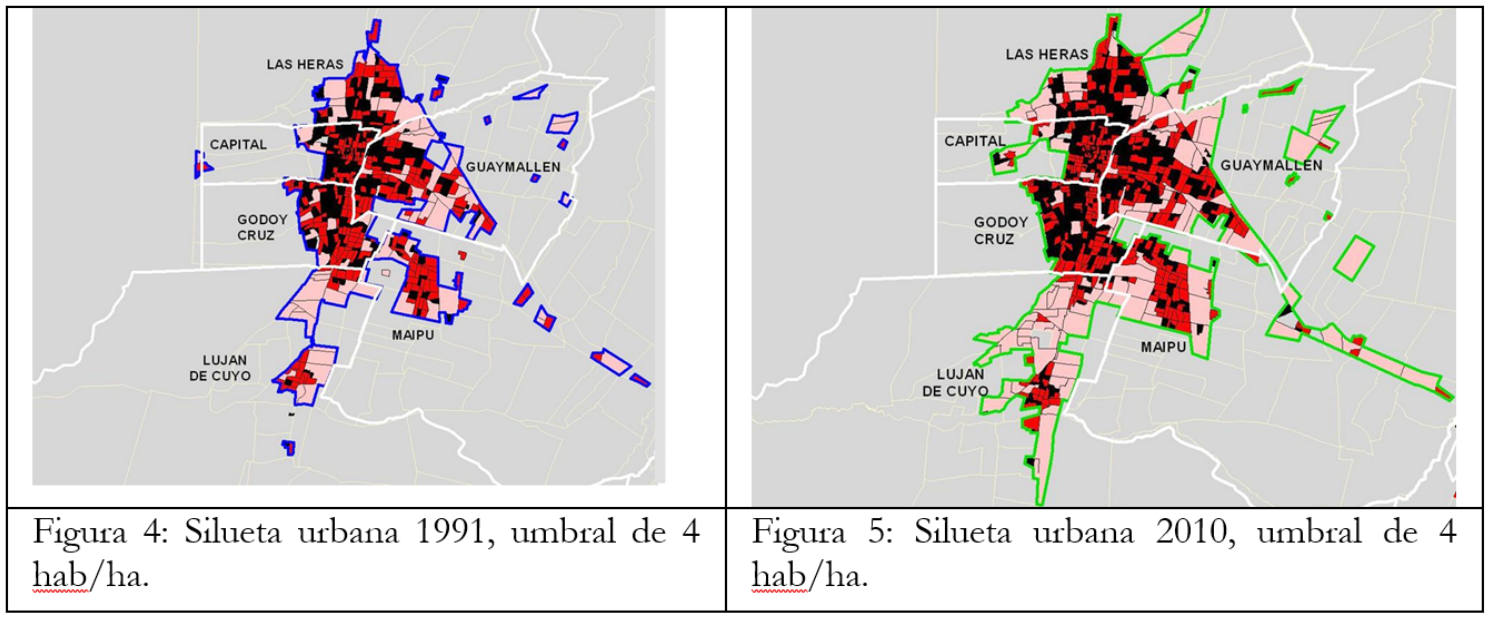

La comparación entre los censos de 1991 y 2010 muestra que se ha ampliado considerablemente la franja de 4 a $20 \mathrm{hab} /$ ha., pero se mantiene estable todo el espacio de mayores densidades. Como se observa en la curva, los departamentos que más han crecido son Guaymallén y Las Heras, al norte del área metropolitana. En cambio hacia el sur y sureste, Luján y Maipú se han extendido enormemente con muy bajas densidades. Figuras 4 y 5 .

De los seis departamentos del AMM los resultados obtenidos indican una tendencia general ascendente de población en todos los departamentos con excepción de Capital. La

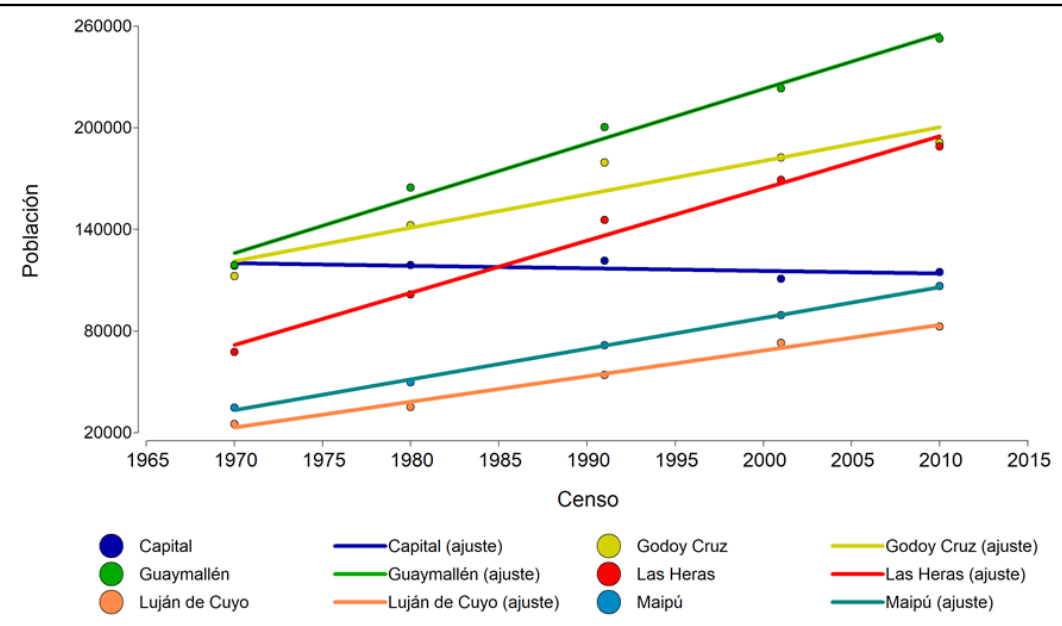

Figura 6: Distribución de población urbana en los departamentos del AMM, 1970 - 2010.

\begin{tabular}{|l|l|l|}
\hline & $\mathrm{R}^{2}$ & Recta ajustada y coeficiente de determinación \\
\hline Capital & 0.35 & Población= 420897,40 -152,67 año \\
\hline Godoy Cruz & 0.90 & Población=-3769056,43+1974,84 año_(*) \\
\hline Guaymallén & 0.99 & Población=-6238382,03+3230,71 año_(***) \\
\hline Las Heras & 0.99 & Población=-6000703,82 +3082,48 año_(***) \\
\hline Luján de Cuyo & 0.99 & Población=-2960660,35+1514,63 año (***) \\
\hline Maipú & 1.00 & Población=-3541415,23 $+1814,65$ año (***) \\
\hline
\end{tabular}

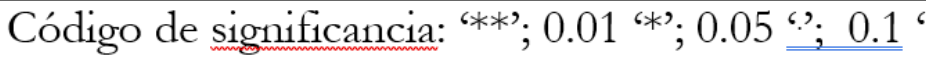

Tab. 2. Recta ajustada y coeficiente de determinación para crecimiento demográfico. 
mayor pendiente de crecimiento poblacional se registró en Guaymallén, seguido por Las Heras, Godoy Cruz, Maipú y Luján de Cuyo (Tabla 2 y figura 6).

\section{A partir de los consumos energéticos}

A partir de datos proporcionados por la Distribuidora de gas Cuyana (ECOGAS) y el Ente Provincial Regulador Eléctrico (EPRE), analizaron los consumos energéticos (Morales, Cucchietti, Arboit, 2017). El análisis del consumo residencial de gas natural por red (2010-2015), se realizó para toda el AMM. El análisis de consumos de energía eléctrica residencial (2004-2010), se realizó para 5 de los 6 departamentos del AMM (exceptuando a Godoy Cruz por la falta en la disponibilidad de datos).

Considerando el consumo residencial de gas por red en el AMM los resultados obtenidos indican una tendencia general ascendente en la totalidad de los departamentos, excepto en el departamento de Capital que registrar una disminución. La mayor pendiente de crecimiento de gas por red se registró en Luján de Cuyo, seguido por Guaymallén y Las Heras (Tabla 3). En el análisis consumo residencial de energía eléctrica la tendencia general es ascendente, Guaymallén es el departamento con el pendiente ascendente mayor seguido por Las Heras y Luján de Cuyo; la menor pendiente se calculó para Maipú (Tabla 3)

\section{Los marcos legales, input del sistema.}

Tal como se representa en el esquema metodológico, se tomaron los marcos legales sobre loteos y las políticas de vivienda, como input al sistema urbano que dinamiza el crecimiento físico de la ciudad. La figura muestra la progresión de leyes sobre subdivisión del suelo, frente a las políticas de vivienda del Instituto Provincial de la Vivienda.

Entre 1990 y 2005 se duplica la superficie ocupada por el AMM. En adelante, la construcción de vivienda social deja más lugar a la iniciativa privada, con barrios cerrados, créditos $\mathrm{y}$ diversificación de programas. Aunque se inicia el proceso de planificación para el ordenamiento territorial plasmado en ley, también se intercalan leyes de regulación

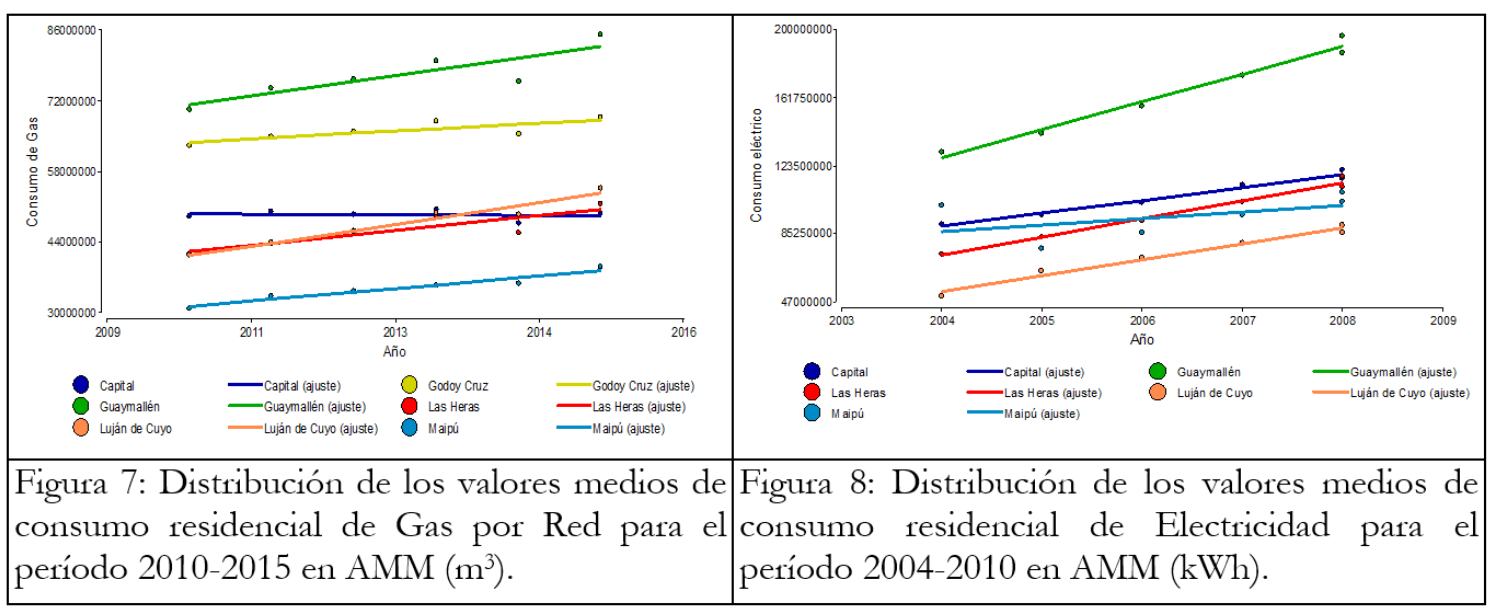

\begin{tabular}{|c|c|c|c|c|}
\hline & \multicolumn{2}{|r|}{ Consumo residencial Gas Natural (m3) } & \multicolumn{2}{|r|}{ Consumo residencial Eléctrico (kWh) } \\
\hline & $\mathrm{R}^{2}$ & \begin{tabular}{|c|} 
Recta ajustada \\
\end{tabular} & $\mathrm{R}^{2}$ & \begin{tabular}{|l|} 
Recta ajustada \\
\end{tabular} \\
\hline Capital & 0.03 & $211203269,16-\quad 80402,34$ año & 0.98 & $\mathrm{E}=-12010064709,17+6038484,65$ año $(* * *)$ \\
\hline Godoy Cruz & 0.69 & $\mathrm{G}=-1724133762,88+889485,48$ año_(*) & & Sin Datos \\
\hline Guaymallén & 0.74 & $G=-4612175485,40+2330001,37$ año $\left(^{*}\right)$ & 0.99 & $\mathrm{E}=-25907932726,05+12993694,98$ año $\left.{ }^{* * *}\right)$ \\
\hline Las Heras & 0.78 & $G \equiv 3356323626,17+1690727,66$ año $\left(^{*}\right)$ & 0.99 & $\mathrm{E}=-16676328058,92+8359271,39$ año $(* * *)$ \\
\hline Luján de C. & 0.95 & $\mathrm{G}=-4931498525,06+2474020,55$ año $(* *)$ & 0.99 & $E=-12754663049,09+$ \\
\hline Maipú & 0.88 & $G=-2549948355,47+1285034,60$ año $(* *)$ & 0.52 & $E \equiv-8665892256,83+$ \\
\hline
\end{tabular}

Tab.3. Recta ajustada y coeficiente de determinación para consumo residencial gas natural y eléctrico. 

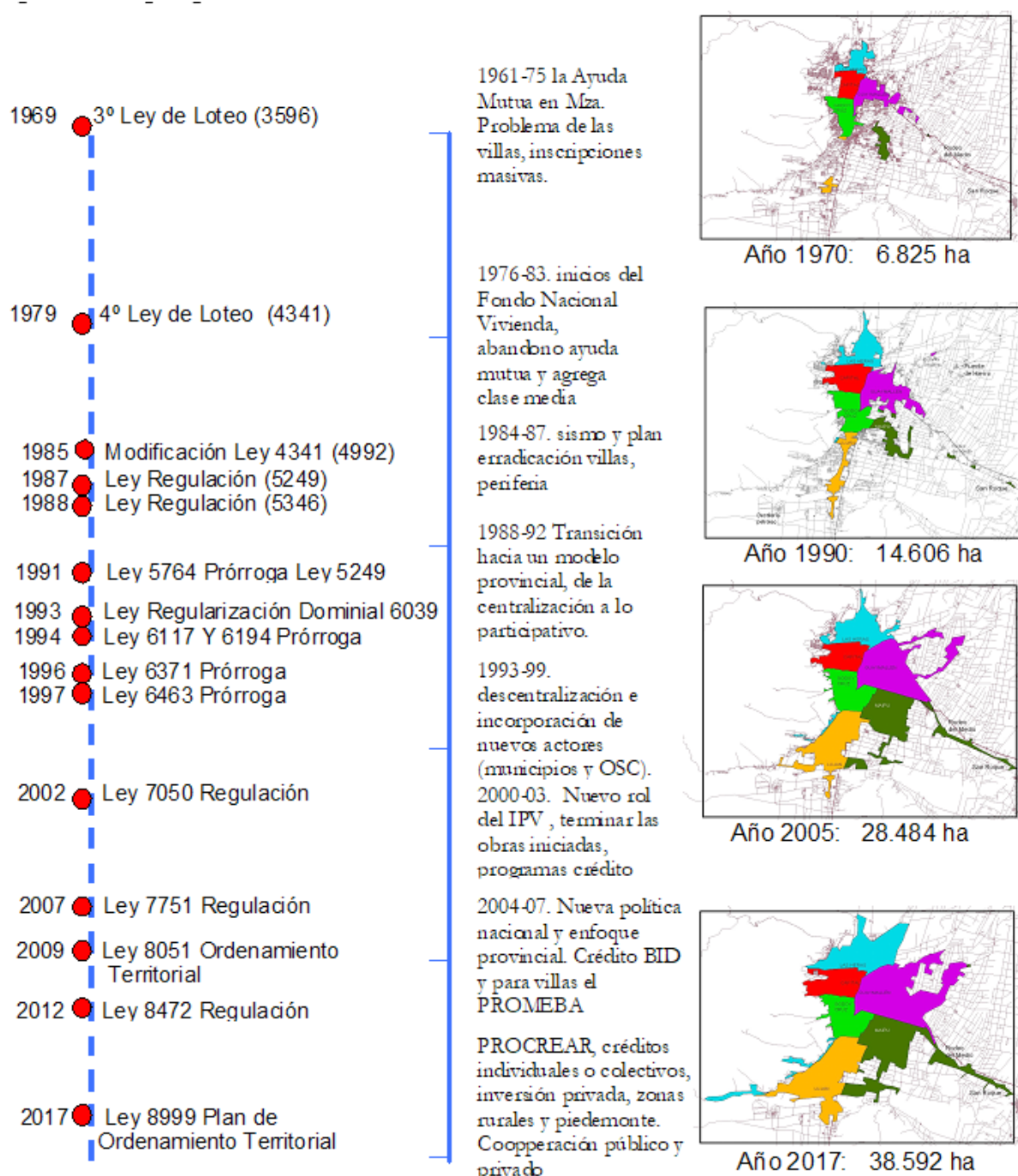

Fig. 9. Leyes de loteo y políticas de vivienda entre 1970 y 2017.

para salvar los hechos no controlados. Entre 2005 y 2017 el área urbanizada adopta un modelo de ciudad dispersa comprometiendo más de 38 mil hectáreas, cubriendo suelos que eran lo mejor para viñedos, chacras y frutales del oasis norte.

El resultado de esta confrontación es bastante revelador. El Estado parece ser sólo un espectador más, en contrapunto con un discurso de avanzada, donde su función de controlador y planificador del territorio queda totalmente relegada frente a otros factores. Con la intención de detener los impactos de procesos nocivos y que también pueda contener y ensamblar las visiones e intereses de los actuales protagonistas, se proponen alternativas de ciudad compacta, difusa, periferia agrícola, piedemonte. En el día a día, el marco de referencia para estas decisiones está tironeado entre las tensiones de la política, la normativa y las demandas urgente, en una rutina que se construye más por repetición que por reflexión.

Aproximadamente se podrían establecer tres etapas, entre 1950 y 1980 , de aquí hasta el 2000 y luego en adelante. La primera con leyes de loteo y políticas centralizadas de vivienda, dirigidas a beneficiarios de los grandes gremios, clase media en general y para erradicación de villas. En la segunda etapa, ya en un contexto de gobierno democrático y con la interferencia de un terremoto (1985), se pasa progresivamente a una descentralización en la construcción de barrios hacia los municipios. Se produce una dispersión muy negativa en el territorio, desorden que coincide con leyes 
de regulación, ampliación de plazos e intentos de encuadrar los hechos dentro de alguna normativa.

\section{Los índices de vegetación, output del sistema.}

A partir del análisis de imágenes satelitales Landsat 5 (1986-2011) se calcularon valores medios de los índices de vegetación (VIs) en el AMM (Arboit, Maglione, 2018). Los resultados obtenidos indican una tendencia general decreciente de valores medios del Índice de Vegetación de Diferencia Normalizada (NDVI), (Chuvieco, 2002) y una correlación en la disminución del Índice de Vegetación Ajustado al Suelo (SAVI), (Huete, 1994; CONAE, 2016), considerando la estación de verano en 25 años de estudio (Figura 10). A escala departamental la caída más evidente en los valores de los índices de vegetación se produjo en el departamento de Maipú, seguida por el área urbana de Guaymallén y Las Heras. El departamento de Capital, en el mismo período, es el que mejor conservó su vegetación urbana (Figura 11).

Así como la consecuencia ambiental directa del proceso de expansión urbana ha sido la progresiva pérdida de densidad vegetal en las áreas intra urbanas, ocurre algo semejante con el avance sobre el entorno rural.

En la figura están representadas las siluetas del AMM sobre el oasis norte de Mendoza, donde se destaca también la importancia de las superficies que dependen del sistema de riego superficial. El voraz consumo de terrenos para extender las áreas residenciales con muy baja densidad, es mucho más que una competencia entre lo rural y lo urbano, es una pérdida de recursos económicos agrícolas y una pérdida de servicios ecosistémicos para la población. En efecto, ya están casi consumidos los mejores suelos con derechos de riego y esos espacios no son reemplazables por los ubicados en el borde del oasis.

\section{Resultados de correlación: Análisis estadístico de los resultados}

Se realizó un análisis de estimación de tendencias y correlaciones entre los datos originales ( $\sin$ distinguir departamento sobre el AMM).

Existe correlación negativa de NDVI con la totalidad de las variables analizadas. Se da una correlación negativa moderada entre NDVI y población es decir a medida que aumenta población disminuye el índice de vegetación. La superficie urbana tiene una correlación positiva muy alta con población y moderada con consumo residencial de electricidad. Las mayores correlaciones positivas de la población se dan con el consumo residencial de

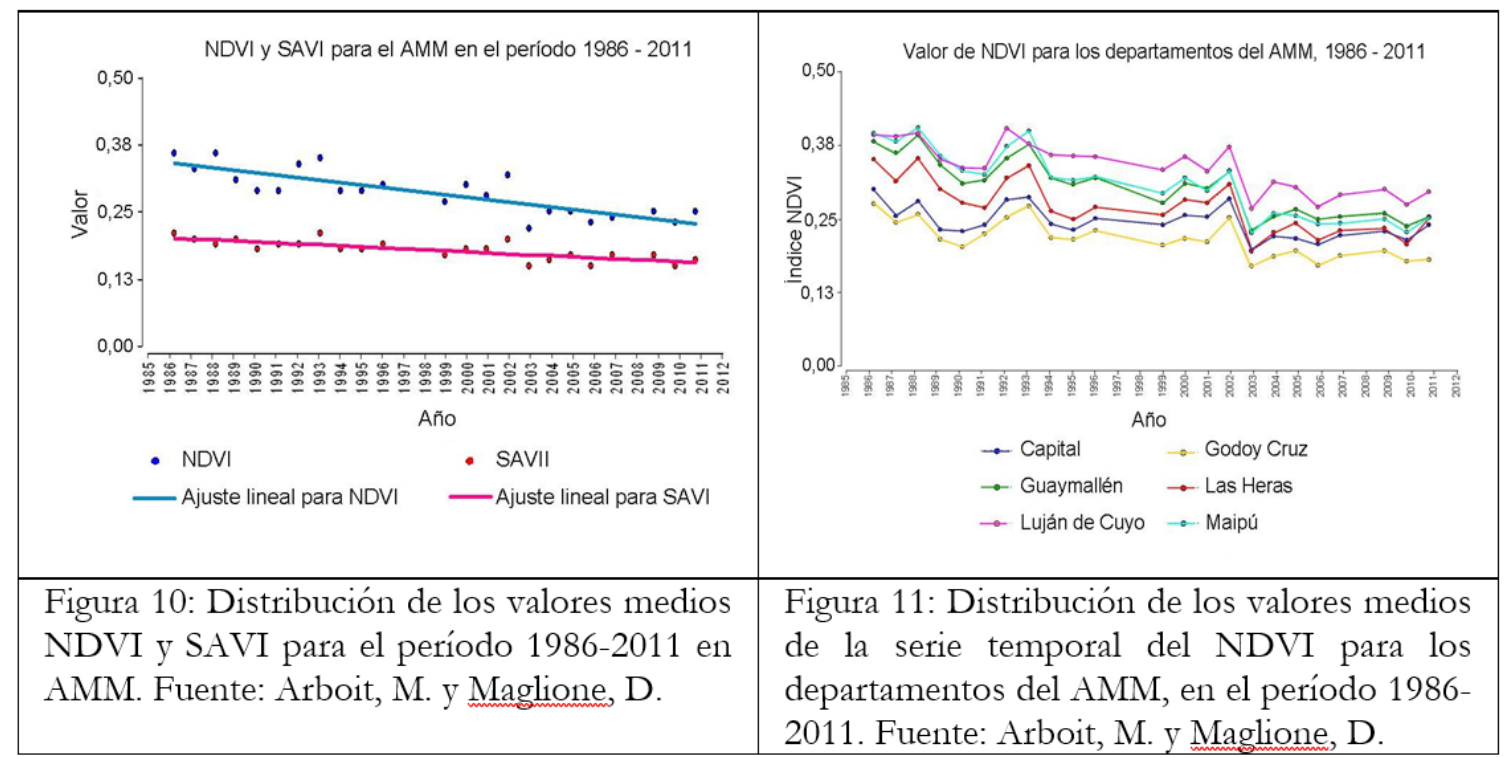

Fig. 6. Proyecto urbano desarrollado en el Taller Guasave, con el paso del Río Sinaloa por Guasave como entorno de localización. Proyecto "Petatlán entre Milpas" 


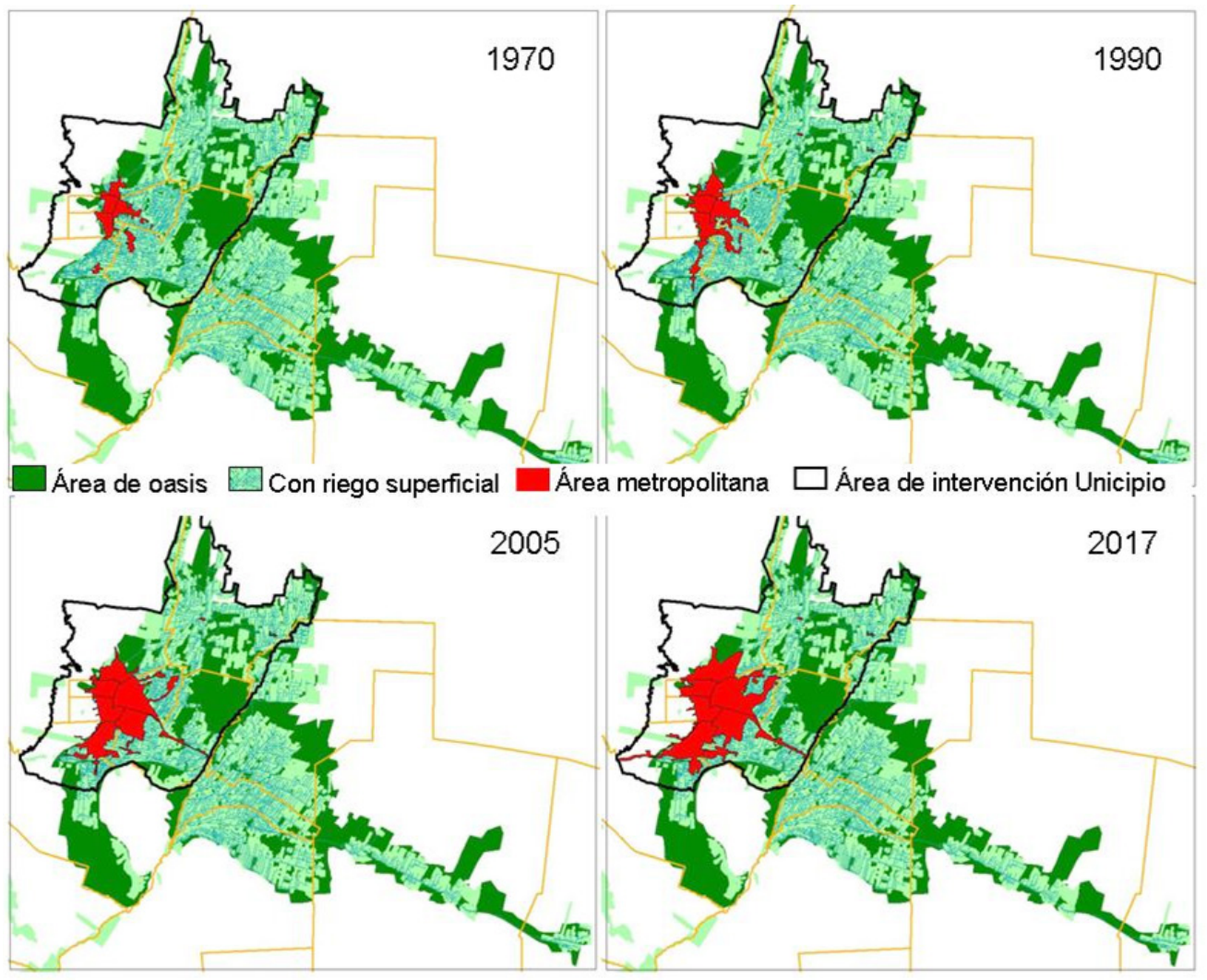

Fig. 12. expansión urbana en el oasis norte de Mendoza.

gas y eléctrico, es decir de aumentar la primera aumentan significativamente las dos restantes. En tanto se da una correlación positiva muy alta entre el consumo residencial de gas y eléctrico (Tabla 4).

Debido a que en cada departamento, no hay mucha coincidencia en cuanto la existencia de datos en forma conjunta para una misma fecha y el valor de NDVI, sólo fue posible calcular las correlaciones entre éste último y el consumo residencial eléctrico, los datos indican que existen una correlación negativa moderada de NDVI con consumo residencial eléctrico en los departamento con información a excepción de Capital.

\section{Análisis estadístico por departamento}

Usando los modelos estimados para las distintas variables y departamentos, se estimaron valores para poder realizar algunas conclusiones más generales (aunque no tan rigurosas por ser valores aproximados). La única que se desestimó fueron los valores de consumo de gas para Capital, ya que el modelo obtenido no es bueno $(\mathrm{R} 2=0.03)$.

\begin{tabular}{|l|r|r|l|l|l|}
\hline & NDVI & $\begin{array}{c}\text { Sup. } \\
\text { Urb. }\end{array}$ & Pob. & Gas & Elec. \\
\hline NDVI & 1,00 & & & & \\
\hline Sup.Urb. & $-0,13$ & 1,00 & & & \\
\hline Pob. & $-0,43$ & 0,93 & 1,00 & & \\
\hline Gas & $-0,33$ & & 0,79 & 1,00 & \\
\hline Elec. & $-0,23$ & 0,49 & 0,89 & 0,92 & 1,00 \\
\hline
\end{tabular}

Tabla 4: Correlación de Pearson: Coeficientes $\backslash$ probabilidades. Con datos originales.

\begin{tabular}{|r|c|}
\hline Capital & 0,02 \\
\hline Guaymallén & $-0,40$ \\
\hline Las Heras & $-0,44$ \\
\hline Luján de Cuyo & $-0,52$ \\
\hline Maipú & $-0,46$ \\
\hline
\end{tabular}

Tabla 5: Correlación entre NDVI y Consumo eléctrico 
Existen diferencias por departamento al modelar el NDVI y consumos residenciales (gas y eléctricos) en función de las variables estimadas, población y superficie urbana.

Donde menos impacta el crecimiento demográfico y la expansión urbano-edilicia sobre la componente ambiental y energética estudiada es en Capital, con correlaciones casi nulas. Por lo que una densificación poblacional en Capital podría considerarse como estrategia ante la problemática planteada; seguido por Godoy Cruz, este último posee altas correlaciones por lo que debería estudiarse las estrategias con mayor detalle. Excluyendo Capital en los restantes departamentos existe correlación de la población y la superficie urbana sobre el resto de las variables.

Existen correlaciones muy altas entre crecimiento demográfico, expansión de la superficie urbana y consumos energéticos en Guaymallén, Luján, Las Heras, Maipú y Godoy Cruz.

Al analizar los modelos para NDVI en Maipú, Godoy Cruz y Las Heras las correlaciones entre NDVI, el impacto población y la superficie urbana es negativa y moderada. En Guaymallén, Luján y Maipú la correlación es negativa y alta.

Los impactos negativos mayores sobre la disminución del NDVI considerando aumento demográfico y expansión urbano-edilicia se han producido según un orden descendente en los departamentos de: Maipú, Guaymallén, Luján de Cuyo, Godoy Cruz y Las Heras. Capital posee la correlación negativa más baja sobre la vegetación por el incremento de superficie urbana y una correlación prácticamente nula con población (Tabla 6).

\section{Conclusiones}

El AMM contiene, al menos, un conflicto histórico entre la dimensión territorial, la dimensión ambiental y la dimensión administrativa. Los tres puntos de vista pueden arrojar resultados muy diferentes, (tamaños y crecimiento de los 6 núcleos urbanos) (interfaces ciudad/campo y campo/

\begin{tabular}{|l|c|c|c|r|r|}
\hline CAPITAL & $\begin{array}{c}\text { Pob. } \\
\text { EST }\end{array}$ & $\begin{array}{c}\text { Sup. } \\
\text { Urb. } \\
\text { EST }\end{array}$ & $\begin{array}{l}\text { Gas. } \\
\text { EST }\end{array}$ & $\begin{array}{c}\text { Elec. } \\
\text { EST }\end{array}$ & $\begin{array}{c}\text { NDVI } \\
\text { EST }\end{array}$ \\
\hline Pob. EST & 1,00 & & & & \\
\hline Sup.Urb. & $-0,21$ & 1,00 & & & \\
\hline Gas EST & - & - & 1,00 & & \\
\hline Elec. EST & $-0,20$ & 0,99 & - & 1,00 & \\
\hline NDVI EST & $-0,04$ & $-0,47$ & - & $-0,49$ & 1,00 \\
\hline
\end{tabular}

\begin{tabular}{|l|c|c|c|c|c|}
\hline $\begin{array}{l}\text { GODOY } \\
\text { CRUZ }\end{array}$ & $\begin{array}{c}\text { Pob. } \\
\text { EST }\end{array}$ & $\begin{array}{c}\text { Sup. } \\
\text { Urb. } \\
\text { EST }\end{array}$ & $\begin{array}{c}\text { Gas. } \\
\text { EST }\end{array}$ & $\begin{array}{c}\text { Elec. } \\
\text { EST }\end{array}$ & $\begin{array}{c}\text { NDVI } \\
\text { EST }\end{array}$ \\
\hline Pob. EST & 1,00 & & & & \\
\hline Sup.Urb. & 0,94 & 1,00 & & & \\
\hline Gas EST & 0,96 & 0,96 & 1,00 & & \\
\hline Elec. EST & - & - & - & 1,00 & \\
\hline NDVI EST & $-0,61$ & $-0,62$ & $-0,63$ & - & 1,00 \\
\hline
\end{tabular}

\begin{tabular}{|l|r|r|r|r|r|}
\hline $\begin{array}{l}\text { GUAYMA } \\
\text {-LLÉN }\end{array}$ & $\begin{array}{r}\text { Pob. } \\
\text { EST }\end{array}$ & $\begin{array}{r}\text { Sup. } \\
\text { Urb. } \\
\text { EST }\end{array}$ & $\begin{array}{l}\text { Gas. } \\
\text { EST }\end{array}$ & $\begin{array}{l}\text { Elec. } \\
\text { EST }\end{array}$ & $\begin{array}{c}\text { NDVI } \\
\text { EST }\end{array}$ \\
\hline Pob. EST & 1,00 & & & & \\
\hline Sup.Urb. & 1,00 & 1,00 & & & \\
\hline Gas EST & 0,99 & 0,99 & 1,00 & & \\
\hline Elec. EST & 1,00 & 1,00 & 0,99 & 1,00 & \\
\hline NDVI EST & $-0,76$ & $-0,76$ & $-0,75$ & $-0,76$ & 1,00 \\
\hline
\end{tabular}

\begin{tabular}{|l|r|r|r|r|r|}
\hline $\begin{array}{l}\text { LAS } \\
\text { HERAS }\end{array}$ & $\begin{array}{r}\text { Pob. } \\
\text { EST }\end{array}$ & $\begin{array}{r}\text { Sup. } \\
\text { Urb. } \\
\text { EST }\end{array}$ & $\begin{array}{l}\text { Gas. } \\
\text { EST }\end{array}$ & $\begin{array}{c}\text { Elec. } \\
\text { EST }\end{array}$ & $\begin{array}{c}\text { NDVI } \\
\text { EST }\end{array}$ \\
\hline Pob. EST & 1,00 & & & & \\
\hline Sup.Urb. & 0,91 & 1,00 & & & \\
\hline Gas EST & 0,99 & 0,91 & 1,00 & & \\
\hline Elec. EST & 0,99 & 0,92 & 0,99 & 1,00 & \\
\hline NDVI EST & $-0,57$ & $-0,53$ & $-0,58$ & $-0,59$ & 1,00 \\
\hline
\end{tabular}

\begin{tabular}{|l|c|c|c|c|c|}
\hline LUJÁN & $\begin{array}{c}\text { Pob. } \\
\text { EST }\end{array}$ & $\begin{array}{c}\text { Sup. } \\
\text { Urb. } \\
\text { EST }\end{array}$ & $\begin{array}{l}\text { Gas. } \\
\text { EST }\end{array}$ & $\begin{array}{c}\text { Elec. } \\
\text { EST }\end{array}$ & $\begin{array}{c}\text { NDVI } \\
\text { EST }\end{array}$ \\
\hline Pob. EST & 1,00 & & & & \\
\hline Sup.Urb. & 0,99 & 1,00 & & & \\
\hline Gas EST & 0,99 & 1,00 & 1,00 & & \\
\hline Elec. EST & 0,99 & 1,00 & 1,00 & 1,00 & \\
\hline NDVI EST & $-0,70$ & $-0,72$ & $-0,71$ & $-0,71$ & 1,00 \\
\hline
\end{tabular}

\begin{tabular}{|l|r|r|r|r|r|}
\hline MAIPÚ & $\begin{array}{r}\text { Pob. } \\
\text { EST }\end{array}$ & $\begin{array}{c}\text { Sup. } \\
\text { Urb. } \\
\text { EST }\end{array}$ & $\begin{array}{c}\text { Gas. } \\
\text { EST }\end{array}$ & $\begin{array}{c}\text { Elec. } \\
\text { EST }\end{array}$ & $\begin{array}{c}\text { NDVI } \\
\text { EST }\end{array}$ \\
\hline Pob. EST & 1,00 & & & & \\
\hline Sup.Urb. & 1,00 & 1,00 & & & \\
\hline Gas EST & 1,00 & 1,00 & 1,00 & & \\
\hline Elec. EST & 0,96 & 0,95 & 0,96 & 1,00 & \\
\hline NDVI EST & $-0,81$ & $-0,82$ & $-0,81$ & $-0,77$ & 1,00 \\
\hline
\end{tabular}

Tab. 6. Correlación de Pearson: Coeficientes\probabilidades por departamento. 
desierto) (normativas provinciales y decisiones municipales)

Aunque siempre estará la visión y actuación jerárquica entre las 3 dimensiones, el desafío aún sigue siendo encontrar cuál es la que deber primar cada vez que se decide sobre el territorio.

Se observa una paradoja. De una parte, se da una alta valoración de la naturaleza que lleva a la expansión de baja densidad con una apropiación de la naturaleza en barrios privados insertos en la trama rural. De otra, con la disminución de los índices de vegetación se infiere la pérdida de pautas urbanísticas que daban a la ciudad una identidad unida al arbolado y las acequias.

Sobre el modelo más conveniente de ciudad, ha quedado demostrado que la ciudad compacta es más eficiente en términos ambientales y energéticos que la ciudad difusa, que implica el consumo de suelo, crecimiento del consumo energético de gas y electricidad y pérdida de los índices de vegetación.

El desafío metodológico se puede sintetizar en la complementación de varios puntos de vista, para el diagnóstico y para la intervención:

1.Abordaje complejo del sistema/ciudad donde la dialéctica entre espacios construidos, elementos verdes mitigantes y demandas sociales urgentes, permita articular las dimensiones espacial, temporal y escalar. Esto es fundamental para justificar el recorte territorial al diagnosticar los problemas.

2.Recomendación de mantener modificaciones incrementales y progresivas de áreas verdes superficiales y cubiertas arbóreas en el ámbito público y privado, que permita afianzar el modelo de ciudad forestada. Los umbrales a respetar deberían plasmarse en indicadores verdes para los códigos de edificación urbana, especies de bajo consumo hídrico, modernización de la infraestructura de riego.

3.Según los resultados debería crecer demográficamente Capital, seguido por Godoy Cruz e intentar revertir la tendencia de crecimiento hacia áreas periféricas, puesto que Maipú, Guaymallén y Luján de Cuyo son los más comprometidos en la pérdida de suelos agrícolas. Podría ser Las Heras, hacia el norte con los acondicionamientos necesarios.
Si bien los resultados demuestran que la ciudad compacta es más eficiente en términos ambientales y energéticos que la ciudad difusa, para ajustar con resultados más contundentes sería conveniente profundizar las mediciones con otros elementos. Desde otros puntos de vista, económico, socio-cultural y técnico ambiental, se presentan disyuntivas que se vinculan más con alternativas de decisión política que con pautas pretendidamente objetivas. Por ejemplo oferta de suelo apto para las funciones urbanas, tomando en cuenta los riesgos sísmico y aluvional; demanda de vivienda por el aumento de población; existencia de terrenos rurales pocos rentables; nuevas tendencias culturales de la población.

\section{Referencias}

ARBOIT, M. \& MAGLIONE, D. (2018). Situación actual y cambios recientes en los índices de vegetación (vis) en ciudades forestadas con climas secos. Caso área metropolitana de Mendoza, Argentina. Urbano, vol. 21, issue 38, pp. 18-35. DOI: https://doi.org/10.22320/07183607.2018.21 .38 .02

CHUVIECO, Emilio. (2002). Teledetección ambiental: la observación de la Tierra desde el espacio. Barcelona: Ariel.

COMISIÓN NACIONAL DE ACTIVIDADES ESPACIALES (CONAE). Índices espectrales derivados de imágenes satelitales Landsat 8 Sensor OLI. Guía de Usuario [en línea]. [Consultado 7 septiembre 2016]. Disponible en: https:// catalogos.conae.gov.ar/landsat8/Docs/ IndicesEspectralesDerivadosDeLandsat8. pdf.

CUERVO, L., Guerrero, F. (editores) (2018) Prospectiva en América Latina. Aprendizajes a partir de la práctica. Serie 88 , Seminarios y Conferencias. Santiago de Chile, CEPAL, Naciones Unidas, ISSN 1680-9041 (versión electrónica)

GOBIERNO DE MENDOZA (2007) 60 Años de Historia 1947-2007 Instituto Provincial de la Vivienda. Mendoza, IPV. $110 \mathrm{p}$

HUETE, Alfredo y LIU, Hongqing. (1994). An error and sensitivity analysis of the atmospheric- and soil-correcting variants 
of the NDVI for the MODIS-EOS. IEEE Transactions on Geoscience and Remote Sensing, vol. 32, pp. 897-905.

MOLINA, G., SEDEVICH, A.; SUDEN, C., DOMIZIO, C. (2018) Contrapunto entre visiones complejas y acciones simplistas: el área metropolitana de Mendoza, en VI Encuentro Latinoamericano de Metodología de las Ciencias Sociales, Cuenca (Ecuador), 7 al 9 de noviembre 2018.

http://elmecs.fahce.unlp.edu.ar/lugar-derelizacion

MORALES, J.; ARBOIT, M.; CUCCHIETTI, C. (2017). Situación del consumo energético reciente en el ambiente construido del área metropolitana de Mendoza. V Jornadas Nacionales y I Internacionales de Investigaciones Interdisciplinarias Regionales. Enfoques para la historia.

WENXUAN Xie, QINGXU Huang, CHUNYANG He, XUE Zhao (2018) Projecting the impacts of urban expansion on simultaneous losses of ecosystem services: A case study in Beijing, China. Ecological Indicators. journal homepage: www.elsevier.com/locate/ecolind. 